\title{
ESCOLA COMPLEMENTAR COMO ESPAÇO DE FORMAÇÃO
}

Flávia Obino Corrêa Werle’

SÍNTESE - Análise dos processos de formação do professor. Situa inicialmente as alternativas de constituição dos agentes do sistema políticoadministrativo da educação do final do período imperial para focalizar as estratégias formativas adotadas pela Escola Complementar, analisando para tanto entrevistas, documentos iconográficos e escritos. A delimitação espacial do estudo é a Provincia de São Pedro do Rio Grande do Sul, Brasil.

\begin{abstract}
This paper analyses the processes of formation of a teacher. The article initially locates the alternatives of constitution of the agents of the political-administrative system of education at the end of the Imperial Period in order to focus on the formative strategies adopted by the Complementary School. For this purpose we have analyzed interviews, iconographic documents and writings. The spatial delimitation of the study is the Província de São Pedro do Rio Grande do Sul, Brazil.
\end{abstract}

\section{Escola Normal Primária:}

\section{a formação do professor para classes de primeiras letras}

A educação sistemática é um elemento central na organização da sociedade e estruturação do sistema político-administrativo da educação na medida em que auxilia a constituir competências, profissões e profissionais.

Para se constituir como professor público o cidadão apenas se submetia a um exame quando eram verificados os conhecimentos que possuía e seu comportamento ético e moral.

O controle sobre as candidatas ao magistério era muito intenso. A ênfase na verificação da moralidade do candidato demonstrava a importância da instrução pública para o controle do comportamento social mais do que para a transmissão do conhecimento, ênfase que não desaparece com a criação de cursos para a formação de professores. O comportamento moral é matéria de controle tanto nos exames de entrada de candidatos aos cursos de formação dos professores como se desdobra e amplia em verificações e práticas ao longo do processo de formação.

- Professora e pesquisadora na Faculdade de Educação da PUCRS e da UNISINOS.

\begin{tabular}{|l|l|l|l|l|l|}
\hline VERITAS & Porto Alegre & v. 42 & $\mathrm{n}^{2} 2$ & Junho 1997 & p. 307-316 \\
\hline
\end{tabular}


Quando e de que forma tinham sido obtidos os saberes sobre o mister de ensinar não estava sob análise. Não havia maior especificação sobre os critérios aceitáveis tanto no que se refere ao domínio das matérias como a sua metodologia. Não havia exigência de conhecimentos técnicos específicos para os examinadores. Entretanto este era o rito de institucionalização e criação do profissional professor.

Só posteriormente se institucionalizou como rito de iniciação profissional a escolarização obtida em cursos específicos de formação de professores que propunham a garantia de competências e conhecimentos de melhor nivel.

Assim, no periodo imperial o magistério público era exercido por indivíduos portadores de título de capacidade profissional obtido mediante exame.

Pelo Regulamento da Instrução Pública da Província de São Pedro do Rio Grande do Sul, de 1857, as escolas públicas primárias eram divididas em duas classes: as de instrução elementar, denominadas escolas de $1^{10}$ grau, e as de instrução primária superior, com a denominação de escolas de $2^{2}$ grau.

O magistério público só poderia ser exercido por cidadãos brasileiros que comprovassem maioridade legal, moralidade e capacidade profissional. Para se candidatarem as professoras deveriam exibir, se casadas, a certidão de seu casamento, se viúvas, a de óbito do seu marido, e se vivessem separadas, a pública forma da sentença que julgou a separação para que fosse avaliado o motivo que a originou. As solteiras só poderiam exercer o magistério público tendo 25 anos completos de idade, salvo se ensinassem na casa de seus pais e estes fossem de reconhecida moralidade.

A capacidade profissional deveria ser provada por exame oral e escrito na presença de três examinadores, sendo um deles o Inspetor Geral de Instrução Pública. O exame deveria versar sobre o conteúdo das matérias de ensino e 0 sistema prático e método de ensino. Para as professoras mulheres haveria ainda o exame de trabalhos de agulha.

O estado da instrução pública era precário. Para as autoridades havia necessidade de formar sistematicamente os professores e ampliar os serviços de inspeção das escolas de instrução pública.

No ano de 1871 o governo da Província de São Pedro do Rio Grande do Sul decidiu estabelecer uma Escola Normal Primária para habilitar os aspirantes ao magistério público do sexo masculino. ${ }^{1}$

O ensino nesta escola deveria ser dividido em três anos compreendendo: instrução moral e religiosa, leitura, caligrafia, lingua nacional e pedagogia, aritmética, álgebra até equações de $2^{\circ}$ grau, geometria prática, desenho linear e escrituração mercantil, elementos de geografia do Brasil e especialmente história e geografia da provincia, noções de ciências físicas e naturais aplicáveis aos usos da vida.

Verifica-se que os saberes contemplados eram de cunho geral havendo menção a outros não diretamente relacionados ao trabalho docente como escrituração mercantil. Este conteúdo curricular no qual a Economia Doméstica e Trabalhos de Agulha estavam ausentes referencia o curso a uma clientela masculina. Ademais,

É nas três últimas décadas do Império que as províncias instalam suas escolas normais: $1864 \mathrm{em}$ Pernambuco, 1870 no Pará, 1876 no Paraná, 1883 na Paraiba (Primitivo Moacyr, 1940). 
anexa à Escola Normal Primária deveria funcionar uma "escola primária masculina" para a prática do ensino.

Os candidatos à Escola Normal Primária deveriam passar por severa sindicância prévia à matrícula para verificar as condições morais para o exercício do magistério. Deveriam também passar por um exame em que demonstrassem se sabiam ler e escrever corretamente, se observavam as principais regras de ortografia e da gramática nacional, e se dominavam a prática das quatro operações elementares de aritmética e tivessem conhecimento das principais doutrinas da religião do estado.

No processo de formação, a conduta dos alunos deveria receber especial atenção do diretor e professores. Os alunos que tivessem vícios que os tornassem impróprios para o magistério seriam excluídos da escola por determinação do presidente da provincia tendo por base as referências do diretor e do conselho diretor da escola.

Para que a institucionalização da formação do professor, mediante a criação da Escola Normal Primária se impusesse foram necessárias medidas reforçando sua importância alocando aos que nela estudassem direitos e capacidades distintivas das demais pessoas que já vinham exercendo o magistério.

A instalação de uma escola para formar professores foi circundada de medidas que a tornavam atrativa e preferivel aos exames e à prática do ensino livre, pela qual o cidadão que desejasse poderia se instalar como professor. Para obter candidatos para a Escola Normal Primária três benefícios foram a ela articulados: nomeação imediata, dispensa de exames, vencimentos mais altos e vitaliciedade no magistério.

Os alunos que concluíssem o curso da Escola Normal Primária seriam nomeados professores públicos independentemente de concurso. A vitaliciedade no magistério só seria declarada quando os professores se mostrassem habilitados no curso da Escola Normal Primária. Ademais, os professores de instrução primária formados pela Escola Normal Primária deveriam ter vencimento um terço maior do que o dos demais. Entretanto, quando não houvesse alunos formados pela escola normal as cadeiras de instrução pública poderiam ser providas por meio de concurso.

As determinações com respeito à seleção, contratação e formação do professor não foram suficientes para atrair professores homens para o magistério de primeiras letras. Os relatórios da instrução pública davam conhecimento da importância de admitir professoras para classes masculinas elementares (Werle, 1996) tendo em vista o afastamento dos homens, seja para o exercício de outras profissões, seja para se dedicarem a classes mais adiantadas.

Embora a Escola Normal Primária tenha sido criada para formar professores do sexo masculino, as mulheres que a freqüentavam ultrapassavam em número os homens que ali estudavam.

Os ideais positivistas vigentes no final do século passado destacavam o papel importante da mulher na formação da sociedade. Assim a necessidade de prover professores para as classes de instrução elementar, a compreensão positivista da centralidade da figura feminina na educação, acrescida da possibilidade de cada 
província organizar, descentralizadamente, a instrução elementar e a formação de professores, oportunizou a criação das Escolas Complementares.

\section{Curso Complementar: \\ a formação da professora pública de classe de primeiras letras}

A formação de professores no Rio Grande do Sul no início do período republicano era ministrada em instituições especiais: Escolas Complementares que sucediam a Escola Elementar e tinham por objetivo:

\footnotetext{
"Art. $3^{\ell}-O$ ensino complementar será ministrado em escolas complementares e destinado a alunos que se mostrarem habilitados nas matérias do curso elementar.

Art. $4^{2}$ - Cada escola complementar terá tantos professores quantos forem necessários, segundo o número de secções em que for dividido o respectivo curso.

Art. $5^{0}-O$ ensino complementar terá, quanto possível, caráter prático e profissional com o fim de desenvolver o ensino elementar e de preparar candidatos ao magistério público primário" (Decreto estadual 874 de 28 de fevereiro de 1906).
}

A partir de 1929, os institutos particulares de ensino secundário, que se submetessem à inspeção do Governo, equipararam-se às Escolas Complementares. Junto com o diploma de conclusão do curso complementar fornecido pelo instituto equiparado o aluno concluinte deveria submeter-se a exames práticos de pedagogia e prática profissional nos quais, quando aprovado davam o direito de exercício do magistério de acordo com o Regulamento da Instrução Pública. Isso ocorreu, pois a formação do professor na Escola Complementar deu-se especialmente pela iniciativa particular o que fazia com que o magistério público primário tivesse seus quadros formados no âmbito do privado. A institucionalização de controles via inspetores e processos de exame asseguravam o papel do Estado no conjunto do sistema político-administrativo da educação.

Os Cursos Complementares (Decreto 4277, 13/03/1929) desenvolviam-se em três anos nos quais eram ministradas as disciplinas de: Português, Francês, Aritmética, Álgebra e Geometria com desenho linear, Geografia Geral, Desenho Figurado, História Geral, do Brasil e Ensino Cívico, Ciências (Física, Química), História Natural e Noções de Higiene, Economia Doméstica, Música e canto Coral, Trabalhos Manuais (masculino e feminino), Educação Física, Pedagogia e Prática Profissional.

O Curso Complementar foi a alternativa de formação de professores que floresceu no Estado até a instalação da Lei Orgânica do Ensino Normal (Decreto-Lei $n^{0}$ 8530, de 02/01/1946) e que articulava, para além dos ditames legais, a formação da jovem de familia de posição social elevada com a de professor de escola elementar. 


\section{Formação da aluna-mestra}

Apresenta-se a seguir a Escola Complementar que, enquanto internato, era uma instituição total assegurando a incorporação de um habitus ligado ao papel da mulher e à constituição da professora. $\mathrm{Na}$ análise do material obtido por entrevistas a ex-complementaristas pode-se levantar a hipótese de que o processo formativo centrava-se no amoldamento do caráter, na formação de atitudes e no saberser mais do que no domínio do conhecimento pedagógico específico.

A Escola Complementar enquanto internato particular feminino era uma instituição abrangente. Os processos formativos envolviam as alunas todo o tempo e em todo o lugar, ultrapassando o rol de disciplinas ministradas. A disciplina era rígida e constante, da manhã até a noite. "Disciplina na maneira de agir, disciplina na maneira de vestir, como estava o uniforme, o laço do pescoço. Se o laço estava torto mandavam endireitar. Verificavam se os aventais estavam limpos, se a mala estava amumada, como estava o armarinho de cada uma, como estava o pente. Era um controle constante e total. Em sala de aula não podia olhar para trás. Nós nunca estávamos sozinhas. No refeitório tinha um estrado onde ficava uma religiosa cuidando como comiamos e quanto comíamos" (Entr. 12).

A disciplina manifestava-se no recreio, na entrada e saida da escola e também na forma de relacionamento entre alunos e professores, caracterizado pela autoridade e distanciamento. Quando o professor entrava na sala todos levantavam e, simplesmente com um gesto de mão, a professora fazia os alunos sentar. Havia polidez no trato. A religiosa que cuidava do dormitório comandava com 0 olhar. As freiras mantinham, entretanto uma certa inacessibilidade: não podiam ser fotografadas e não comiam junto com as alunas.

O externato da escola particular tinha um público de alunas de familias de classe média, enquanto que o internato era freqüentado por filhas de famílias tradicionais e abastadas. Manter uma filha em internato particular era status, distinção e sinônimo de educação primorosa para o que algumas famílias não mediam esforços. Muitas delas moravam nos arredores da escola mas os pais preferiam colocá-las no internato para assegurar a excelência da formação.

A Escola Complementar particular tanto no internato como no externato abrangia todos os aspectos da vida: formação religiosa, formação pedagógica, formação cultural, formação social, formação cívica.

A Escola Complementar pública tinha, tal como a particular, uma disciplina muito rígida; era mista e não mantinha internato mas externato onde as alunas e alunos estudavam em dois turnos.

\footnotetext{
Este subtítulo se estrutura a partir da análise de entrevistas com 17 ex-complementaristas de escolas particulares e públicas, pessoas atualmente situadas na casa dos 70 anos. As entrevistas foram gravadas, transcritas e digitadas em espaço um totalizando 226 páginas. Ao término do Curso Complementar as egressas recebiam o título de aluna-mestra.
} 
Do currículo ${ }^{3}$ das escolas complementares faziam parte matérias como Matemática, Francês, Desenho, Química e Física, Português, Histónia Natural, Ginástica, História Geral, Pintura, Música, Canto Coral, Teoria e Solfejo, Ensino Religioso, Bordado. Aos sábados eram ministradas aulas de civilidade onde as alunas aprendiam boas maneiras e etiqueta social. Era enfatizada a formação cívica, o amor à Pátria cultivado na Escola Complementar, por meio de comemorações, desfiles, canções e conhecimentos sistematizados.

A formação profissionalizante específica era ministrada na disciplina de Pedagogia que incluía elementos teóricos e aulas práticas. Duas ou três alunas do complementar davam aula na escola elementar e a professora assistia para avaliar o trabalho. Não havia estágio no final do curso, mas ao longo de toda a formação. Quanto à prática pedagógica nem todas as entrevistadas apresentam depoimentos convergentes, nem mesmo as que estudaram na mesma escola. Algumas relataram que não aprenderam nada de útil nas aulas de Pedagogia. "Nas aulas de Didática davam fichinhas. A professora regente funcionava como se nós fôssemos as aluninhas e pedia que com as fichinhas formássemos as palavras. Era muito rudimentar. Nunca entrava em sala de aula da escola elementar" (Entr. n³).

O magistério elementar era o futuro comum. "Nós já íamos para lá sabendo que um dia seriamos professoras, querendo ou não, gostando ou não. Estávamos lá para isso. Ficávamos lá, no internato, ia passando o tempo, iamos estudando e sabíamos que íamos ser professoras. Recebemos uma orientação religiosa e o diploma de catequistas para dar educação religiosa. Naquela época mulher só trabalhava sendo professora" (Entr. $\mathrm{n}^{\mathrm{0}}$ 12). Neste depoimento evidencia-se a Escola Complementar como instituição total com controle sobre todos os aspectos da vida das internas e restrito contato com o mundo exterior.

A escola era um local de amizade, mas acima de tudo um local de ordem e disciplina tendo em vista o estudo e o conhecimento.

"Foi uma época maravilhosa, muito gratificante. Íamos internas muito meninas. Quem nos amoldou foram elas. Passamos seis, cinco anos juntas. Morávamos nove meses no ano juntas. Nasce uma amizade maravilhosa. Tudo junto. Dormitório, capela, refeitório, recreio, aula, estudo. Vamos para a rouparia? todo o mundo junto. Vamos para o recreio? todo o mundo junto" (Entr. $\mathrm{n}^{\mathrm{o}} 12$ ).

A Escola Complementar era um local de preparação da mulher e da professora e para tanto se constituiam num lugar de disciplina e estudo. Para abrigar externas que permaneciam dois turnos na escola e alunas internas que viviam na escola e iam para casa de seus pais nas férias de verão e inverno, ou mais amiúde, de dois em dois meses, as escolas públicas e particulares tinham uma grande sala de estudo. "Depois do almoço a gente tinha um pequeno período de repouso, de descanso e das duas até as quatro a gente ia para aquela sala de estudo onde já

\footnotetext{
A não-convergência dos depoimentos nos aspectos especificamente curriculares (disciplinas ministradas, relação teoria-prática) deve-se a muitos fatores. As entrevistadas formaram-se na Escola Complementar pelos anos 40 - 1943, 1944. O tempo portanto pode ser responsável pela imprecisão de informações. As entrevistadas se de uma mesma escola, não pertenceram às mesmas turmas sendo possivel que as matérias curriculares tenham sido diferenciadas. A consulta documental de arquivos da Diretoria de Instrução Pública e de Escolas Complementares não são também convergentes.
} 
se fazia os temas para o outro dia e estudava. Ia para casa pronta. Só na época de prova a gente ainda se esforçava um pọco em casa. Era uma sala bem grande onde iam todas as alunas de todas as séries do complementar, de todas as turmas. Era obrigatório este estudo e tinha um púlpito e uma freira cuidando de lá de cima. A gente só tinha que estudar, quisesse ou não" (Entr. $n^{\circ} 3$ ).

A formação do professor era calcada sobre o hábito de estudo, sobre o saber. A memorização foi referida pela maioria das entrevistadas como estratégia de ensino usual e exclusiva.

A avaliação era exigente, incluindo provas escritas e orais perante banca com vários professores. Examinando as atas de exames de Escolas Complementares percebe-se a severidade da avaliação. Eram três professores examinadores um dos quais presidia a comissão. Realizavam exames escritos e orais e lavravam ata onde indicavam os graus que individualmente atribuiam a cada prova e por fim uma média e uma menção: aprovada com distinção, aprovada plenamente, aprovada simplesmente. Mesmo que apenas uma aluna precisasse prestar exame o processamento e constituição de bancas seguia a mesma formalidade. Havia provas também para ingresso na Escola Complementar. Das bancas das provas de seleção participavam inclusive professores públicos de outros municípios com larga experiência docente, demonstrando uma valorização do saber fazer e da prática profissional.

O mundo do trabalho não foi menos exigente do que o da Escola Complementar.

Os relatos das entrevistadas denotam dedicação para com seus alunos. Lecionaram entre 25 e 32 anos dizendo-se realizadas com o trabalho. Algumas abandonaram o magistério num período mais curto por problemas de saúde ou para dedicarem-se à familia e aos filhos.

Uma das entrevistadas que tinha até o quinto ano do Conservatório de Música começou lecionando na escola elementar mas em breve passou a ser a professora de música da Escola Complementar pública onde havia sido aluna.

"Comecei a lecionar Música porque uma professora de música entrou em licença para tratamento de interesse e o Secretário de Educação acedeu, contanto que ela indicasse uma substituta. Indicou-me" (Entr. $n^{\circ}$ 11). Foi difícil, pois Villa Lobos", apoiado pelo ministro Gustavo Capanema, insistia na importância coletivizadora da música e especialmente do canto orfeônico. A entrevistada dizia-se contra Villa Lobos que queria que alunos do $2^{\circ}$ ano trabalhassem com harmonia. "Nem rádio tinham em Passo Fundo. Tinha piano em algumas casas mas não tocavam. Como é que ia exigir daquelas aluninhas do Complementar que não tinham condições de ouvir - porque em casa não tinham um rádio para transmitir nada... - num horariozinho: três vezes por semana, quarenta minutos. Não tinham noção de ouvido, ritmo, eram musicalmente analfabetos" (Entr. $\mathrm{n}^{\mathrm{o}} 11$ ). Villa Lobos fez força para tirar-lhe a cadeira, "fez queixa contra mim. Marginalizou-me, pois não admitia que o seu programa não fosse dado na escola" (Entr. no 11).

4 Heitor Villa Lobos em 1936 era diretor de educação musical e artistica da cidade do Rio de Janeiro. Em 1930 percorrera mais de 60 cidades paulistas numa cruzada de difusão da música. A música orfeônica recebeu na época apoio e destaque de parte do governo (Schwartzman, et al. 1984). 
A entrevistada adaptava o ensino de Música às conđições dos alunos, dandolhes um cabedal de músicas, partituras que pudessem usar com os seus alunos, sem que precisassem de ninguém para ajudá-los. "Não distinguiam um tango de uma valsa. Não conheciam um instrumento, não teriam quem as acompanhasse em piano nos momentos de ensaio com as crianças. Era preciso que as alunas do Complementar tivessem condições de transmitir e reger. Por isto, como professora de Música dava a todas as alunas um momento de regência. Na Semana da Pátria apresentavam-se em todas as solenidades, em cada uma delas uma aluna diferente era a regente. Não repetia, cada vez era uma, "com isso, perdiam a inibição e regiam direitinho". Chegavam ao $3^{\circ}$ ano do Complementar com quarenta números. Hinos oficiais, datas nacionais, aniversários, canções de roda, canções de despedida. Procurava dar em dó maior por ser a tonalidade que todo o ser humano tem. Fazia a classificação da voz. Se diziam: não tenho voz, não tenho ouvido, argumentava: mas você fala, tem voz e tem ouvido.

Em geral a aluna-mestra assumia o magistério em outra cidade distante de onde morava, não indo para as vilas mas para distritos mais distantes. Uma das entrevistadas foi lecionar numa localidade tendo se hospedado na casa do subprefeito. Como as "professorinhas" eram tidas em grande respeito, eram convidadas para madrinhas de batismo, testemunhas de casamento e até para proceder à encomendação de pessoas falecidas.

Em geral, depois de formada, a professora era nomeada para a zona rural, para uma escola de primeira entrância. Depois de um determinado número de anos ia para escola de segunda entrância.

Muitas alunas-mestras concluíam o Curso Complementar com apenas 17 anos mas apenas com 18 poderiam candidatar-se a um cargo por concurso. Trabalhavam por vezes no inicio da carreira como professoras substitutas. Foi o caso de uma das entrevistadas que nos primeiros quatro anos trabalhou como professora substituta, sem remuneração. Como tinha portaria do governador que a designava substituta, sua atividade docente contava pontos para a aposentadoria. Se fosse substituta sem portaria não teria contado tempo para a aposentadoria. Em geral isso acontecia com aquelas que não tinham completado 18 anos que deviam permanecer como substitutas até atingirem a maioridade para poderem se submeter a um concurso.

Se fossem menores, as mulheres não seriam remuneradas, embora pudessem assumir a responsabilidade de uma classe de alunos. Com a mudança de idade 18 anos - passavam a ser reconhecidas como agentes do sistema políticoadministrativo da educação.

Nas escolas elementares as professoras novas eram recebidas pela direção da escola que apresentava as professoras com maior experiência e que familiarizava as novas na filosofia da escola.

Era comum que as alunas-mestras iniciassem seu trabalho docente em escolas pequenas e com turmas de alunos de diferentes adiantamentos, hoje designadas de classes multisseriadas. Foi o caso de uma das entrevistadas que tinha muito interesse em ensinar. Tendo concluído o curso com 17 anos não poderia pedir nomeação, só com 18. Foi então lecionar (1941) numa escola particular ele- 
mentar no centro da cidade de Bagé atendendo alunos da $1^{\mathrm{a}}$ à $5^{\mathrm{a}}$ série. Entrou usando conjuntamente a silaba, a palavra e a letra e não mais o bê-á-bá. Trazia portanto a inovação didático-pedagógica para a prática escolar. Na época, relatava a entrevistada, o magistério era um sacerdócio. Seu pai tinha uma chácara e no verão lecionava às crianças da chácara situada na zona da campanha. "Vinharn a cavalo, a pé, não tinham condições".

As alunas-mestras, continuava a ex-complementarista, estavam ansiosas pelo saber, ansiosas para ter conhecimentos, ansiosas para sair dali e ensinar. "Eu acho que era rara que não quisesse ser professora."

\section{Processos formativos na Escola Complementar e exigências do trabalho}

Revisando o processo de formação do professor elementar no Rio Grande do Sul verifica-se que os cursos que sistematizam a formação colocaram-se como forma mais adequada para validar e controlar os saberes necessários para o magistério elementar. A formação sistematizada e não o exame se mostrou, ao longo do tempo, a estratégia preferida, embora não exclusiva, na verificação da capacidade profissional do professor. O professor como agente do sistema educativo era por freqüentar a Escola Complementar o portador do habitus desejável para a época.

Se, em 1871, o exame assegurava a capacidade profissional sendo um insțrumento útil para indicar o domínio dos conhecimentos essenciais ao exercício da função, a partir de 1871 a formação da Escola Normal Primária se colocou como preferível. Não foi uma substituição imediata nem total, mas impôs-se. Neste período o sistema político-administrativo da educação passou a expedir diplomas que desempenharam papel determinante na produção das hierarquias deste mesmo sistema como espaço de exercício profissional.

A Escola Complementar, no início do século, reafirmou a importância da formação da professora da escola elementar articulada à formação da mulher para o lar.

Os conhecimentos transmitidos na Escola Complementar nem sempre se organizavam racionalmente em termos de "ser capaz de". Centravam-se no domínio de matérias de educação geral e na formação de atitudes e hábitos assegurando sólida formação. As escolas complementares particulares ofereciam estudos em caráter de internato e externato.

O internato provia uma formação qualificante ampla, não apenas para o desenvolvimento da carreira profissional mas para uma posição na sociedade (papel de mãe e dona de casa). Por outro lado, a instrução pública da época - pouco hierarquizada - considerava os conhecimentos e experiência profissional dos egressos da Escola Complementar permitindo-lhes exercer suas competências, adquirir novas, atendendo a demandas da comunidade onde atuassem como professores.

As demandas da sociedade, a flexibilidade e pouca estruturação do sistema político-administrativo da educação contribuiram para que o professor tivesse grande espaço de ação, e para que o professor tivesse mais possibilidades de criar 
espaços pelo exercício de seus saberes. Embora a Escola Complementar desse prevalência no currículo aos atributos cognitivos, o processo de formação e disciplinamento era muito amplo assegurando o habitus desejável.

Na Escola Complementar o ensino era centrado nos saberes disciplinares e não na produção de competências verificáveis em situações e tarefas específicas. Entretanto as competências requeridas pelas diversas situações profissionais dos egressos demonstram que a Escola Complementar foi além provendo competências que eram tornadas ato pelas alunas-mestras nas situações reais das quais participavam. Assim, só aparentemente os conteúdos de formação e os conteúdos de trabalho não se articulavam na Escola Complementar. Havia um habitus constituído que assegurava tal integração.

\section{Referências bibliográficas}

BOEIRA, Nelson. O Rio Grande do Augusto Comte. IN: GONZAGA, Sérgius (org.) RS: Cultura \& Ideologia. Porto Alegre: Mercado Aberto, 1980. p. 34 - 59.

CUNHA, Célio da. Educação e Autoritanismo no Estado Novo. São Paulo: Cortez, 1981. 176 p.

DESAULNIERS, Julieta Beatriz Ramos. A dinâmica estrutural do campo religioso: alguns dados empíricos. Veritas, Porto Alegre, v.41, n.162, p. 249 - 260, jun. 1996.

FL_ESCH, Irmã Benícia. Seguindo Passo a Passo, uma caminhada: História da Congregação das Irmãs Franciscanas da Penitência e Caridade Cristã no Brasil. Porto Alegre, s. ed., 1993.

MOACYR, Primitivo. A Instrução e as Provincias: subsídios para a História da Educação no Brasil 1834

- 1889 (Espínto Santo, Minas Gerais, Paraná, Santa Catarina, Rio Grande do Sul, Goiás). $3^{2}$ Vol. São Paulo: Companhia Edit. Nacional, 1940.

MOACYR, Primitivo. A Instrução e as Provincias: subsídios para a História da Educação no Brasil 1834 - 1889 Das Amazonas às Alagoas. $1^{\mathfrak{a}}$ vol. São Paulo: Companhia edit. Nacional, 1939.

PAIXÃO, Léa Pinheiro. Mulheres mineiras da República Velha. Profissão: Professora. Educação em Revista. Belo Horizonte, UFMG, n. 14, p. 12-25, dez. 1991.

PINTO, Celi Regina J. Positivismo: um projeto político alternativo. (RS: 1889-1930). Porto Alegre: L\&PM, 1986. 111p.

SCHWARTZMAN, Simon; BOMENY, Helena Maria Bousquet; COSTA, Vanda Maria Ribeiro. Tempos de Capanema. Rio de Janeiro: Paz e Terra, 1984. 388p.

SIMIAND, François. El Codigo y el documento. In: BOURDIEU, Pierre, CHAMBOREDON, Jean-Claude, PASSERON, Jean-Claude. El Oficio de Sociólogo. 11. ed. Mexico: Siglo XXI, 1988, p. 164-66.

TAMBARA, Elomar. Positivismo e Educação. Pelotas: Ed. Universitária/UFPel, 1995.

VARELA, Julia. Genealogia de la Escuela: análisis socio-histórico del processo de institucionalización de la escuela primaria. Tempora $N^{g} 8$. Tenerife, Facultad de Filosofia y Letras, Universidad de la Laguna, p. 13- 36, jul./dic. 1986.

VILLELA, Heloisa de Oliveira Santos. A Primeira Escola Normal do Brasil: uma contribuição à Histónia da Formação de Professores. Niterói: UFF, 1990. 286f. Dissertação (Mestrado em Educação) - Faculdade de Educação, Universidade Federal Fluminense, 1990.

WERLE, Flávia Obino Corrêa. Sistema Político - Administrativo da Educação: análise das relações de poder entre as instâncias federal, estadual e municipal no periodo republicano. Porto Alegre, PUCRS: 1993. 452 p. Tese (Doutorado em Educação). Faculdade de Educação. Pontificia Universidade Católica do Rio Grande do Sul. 